REGARDS

SUR L'ECONOMIE ALLEMANDE

BULLETIN ECONOMIQUE DU CIRAC
Regards sur l'économie allemande

Bulletin économique du CIRAC

$85 \mid 2008$

Varia

\title{
Europe sociale
}

v. der LINDEN Klaus, Umstrukturierung von mitbestimmten Unternehmen nach deutschem Umwandlungsrecht und durch grenzüberschreitende Sitzverlegung / PRUNZEL Regine, Der „Europäische Sozialkonsens“ als Instrument zur Stärkung des „Europäischen Sozialmodells“. Vom politischen Postulat zur eigenständigen sozialpolitischen Säule / VINCENT Gilbert (dir), L'avenir de l'Europe sociale. Solidarités, droit et protections sociales

\section{CpenEdition} Journals

Édition électronique

URL : http://journals.openedition.org/rea/408

DOI : $10.4000 /$ rea. 408

ISBN : 978-2-8218-0866-9

ISSN : 1965-0787

Éditeur

CIRAC

Édition imprimée

Date de publication : 1 mars 2008

ISSN : 1156-8992

Référence électronique

"Europe sociale », Regards sur l'économie allemande [En ligne], 85 | mars 2008, document 3, mis en ligne le 22 avril 2008, consulté le 22 septembre 2020. URL : http://journals.openedition.org/rea/408 : DOI : https://doi.org/10.4000/rea.408

Ce document a été généré automatiquement le 22 septembre 2020.

(c) CIRAC 


\section{Europe sociale}

v. der LINDEN Klaus, Umstrukturierung von mitbestimmten

Unternehmen nach deutschem Umwandlungsrecht und durch grenzüberschreitende Sitzverlegung / PRUNZEL Regine, Der „Europäische Sozialkonsens“ als Instrument zur Stärkung des „Europäischen Sozialmodells“. Vom politischen Postulat zur eigenständigen sozialpolitischen Säule / VINCENT Gilbert (dir), L'avenir de l'Europe sociale. Solidarités, droit et protections sociales

\section{RÉFÉRENCE}

v. der LINDEN Klaus, Umstrukturierung von mitbestimmten Unternehmen nach deutschem Umwandlungsrecht und durch grenzüberschreitende Sitzverlegung, Duncker \& Humblot, Berlin, 2007, 662 p.

PRUNZEL Regine, Der „Europäische Sozialkonsens“ als Instrument zur Stärkung des „Europäischen Sozialmodells“. Vom politischen Postulat zur eigenständigen sozialpolitischen Säule, Duncker \& Humblot, Berlin, 2007, 488 p.

VINCENT Gilbert (dir), L'avenir de l'Europe sociale. Solidarités, droit et protections sociales, L'Harmattan, Paris, 2007, 260 p.

1 Désir ou réalité ? Le «modèle social européen » est au cœur d'innombrables débats, comme le révèle cet ouvrage collectif (VINCENT) qui cherche à éclairer le concept sous l'angle sociétal avec, au cœur des propos, les droits de l'Homme. Mais que recouvre, en fait, cette notion? PRUNZEL tente d'en esquisser les contours juridiques sur la base de la réglementation et de la jurisprudence européennes. Partant du constat que le droit communautaire contient de nombreuses dispositions permettant de définir une politique sociale, l'auteur développe un modèle de " consensus social européen » auquel il ne manquerait plus, pour devenir réalité, que la «volonté politique des Etats membres». Mais l'état actuel du modèle économique européen prévoit déjà un équilibre entre impératifs de concurrence et garantie des droits sociaux, à l'exemple des modes de cogestion introduits par l'adoption du statut de société européenne. Il est vrai toutefois que, dans la pratique (en cas de restructuration, de transfert du siège social...), le droit 
communautaire relatif aux entreprises entre en conflit avec les régulations sociales nationales, de même qu'avec la liberté d'établissement au sein de l'UE (von der LINDEN). (ib) 